\title{
Milestone 2.8: Preliminary Radiolytic Gas Generation Measurements from Helium-Backfilled Samples
}

\section{December 2020}

Elizabeth H. Parker-Quaife and Gregory P. Horne

Idaho National Laboratory, Center for Radiation Chemistry Research

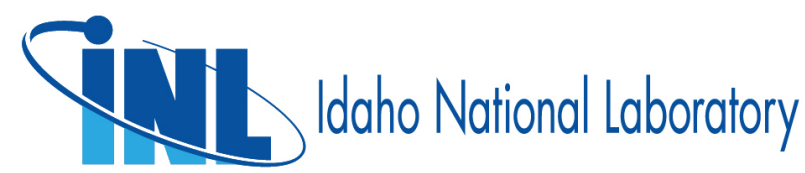




\section{DISCLAIMER}

This information was prepared as an account of work sponsored by an agency of the U.S. Government. Neither the U.S. Government nor any agency thereof, nor any of their employees, makes any warranty, expressed or implied, or assumes any legal liability or responsibility for the accuracy, completeness, or usefulness, of any information, apparatus, product, or process disclosed, or represents that its use would not infringe privately owned rights. References herein to any specific commercial product, process, or service by trade name, trade mark, manufacturer, or otherwise, does not necessarily constitute or imply its endorsement, recommendation, or favoring by the U.S. Government or any agency thereof. The views and opinions of authors expressed herein do not necessarily state or reflect those of the U.S. Government or any agency thereof. 


\section{Milestone 2.8: Preliminary Radiolytic Gas Generation Measurements from Helium-Backfilled Samples}

Elizabeth H. Parker-Quaife and Gregory P. Horne

Idaho National Laboratory, Center for Radiation Chemistry Research

December 2020

Idaho National Laboratory

Center for Radiation Chemistry Research

Idaho Falls, Idaho 83415

http://www.inl.gov

Prepared for the

U.S. Department of Energy

Office of Environmental Management

Under DOE Idaho Operations Office

Contract DE-AC07-05ID14517 
Page intentionally left blank 


\begin{abstract}
The Department of Energy (DOE) is currently managing nearly 13 metric tons of aluminum-clad spent nuclear fuel (ASNF), and some of this ASNF will be placed in helium-backfilled canisters for extended ( $>50$ years) dry storage. Due to in-reactor and cooling pond conditions, oxyhydroxide corrosion layers have formed on the surface of the ASNF elements. These corrosion layers are susceptible to radiolysis and the formation of molecular hydrogen gas $\left(\mathrm{H}_{2}\right)$ due to the fuel's inherent radiation field. Consequently, a rigorous evaluation of the effect of helium gas on radiolytic $\mathrm{H}_{2}$ production is necessary to support the "Technical Considerations and Challenges for Extended ( $>50$ years) Dry Storage of ASNF" program, especially as previous "Task 2 - Oxyhydroxide Layer Radiolytic Gas Generation Resolution" work demonstrated a significant effect of gas composition on the radiolytic yield ( $G$-value) of $\mathrm{H}_{2}$. Here, we report preliminary $G$-values for the radiolytic formation of $\mathrm{H}_{2}$ from the gamma irradiation of pre-corroded aluminum alloy 1100 coupons flame sealed in helium environments. Irradiations yielded $G\left(\mathrm{H}_{2}\right)$ values of $(5.1 \pm 0.5) \quad 10^{-4}$ and $(9.4 \pm$ 0.9) $10^{-4} \mu \mathrm{mol} \mathrm{J}^{-1}$ for pristine coupons, and (10.1 \pm 0.4$) \quad 10^{-4}$ and (15.1 \pm 1.2$)$ $10^{-4} \mu \mathrm{mol} \mathrm{\textrm {J } ^ { - 1 }}$ for pre-corroded coupons for $0 \%$ and $50 \%$ relative humidity, respectively. These helium environment $G\left(\mathrm{H}_{2}\right)$ values are between $28 \%$ and $58 \%$ higher than previously reported values for argon environments. This enhancement is attributed to the significant difference in first ionization energy between helium $(24.59 \mathrm{eV})$ and argon (15.76) facilitating additional processes (e.g., Penning ionization). These new preliminary helium environment $G\left(\mathrm{H}_{2}\right)$ values will be employed by Task 3 - Sealed and Vented System Episodic Breathing and Gas Generation Prediction to model the effect of radiolytic $\mathrm{H}_{2}$ accumulation in helium environments to evaluate the practicality of extended storage in the DOE Standard Canister.
\end{abstract}


Page intentionally left blank 


\section{CONTENTS}

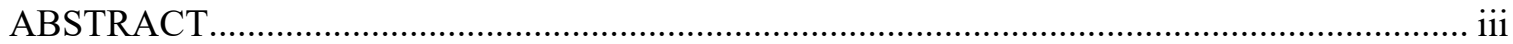

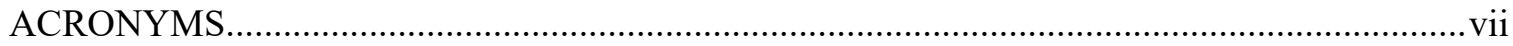

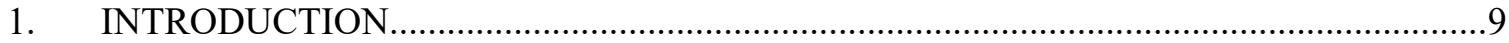

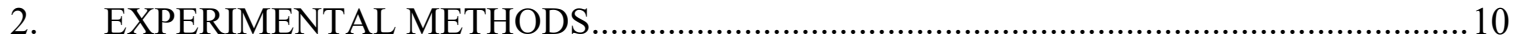

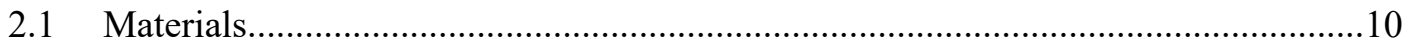

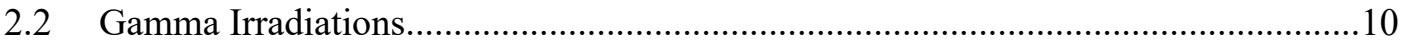

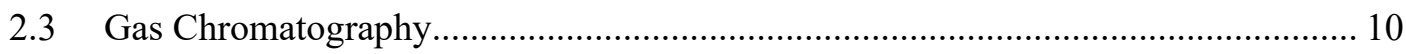

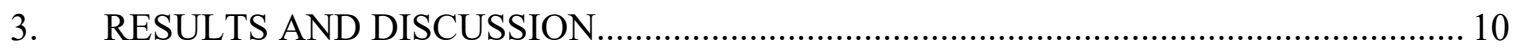

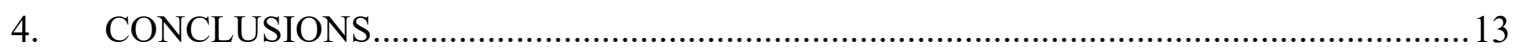

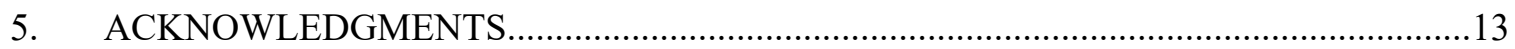

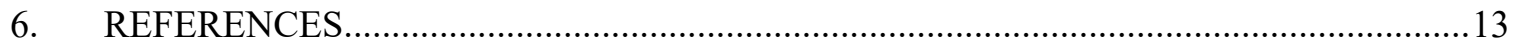

\section{FIGURES}

Figure 1. Concentration of $\mathrm{H}_{2}\left(\mu \mathrm{mol} \mathrm{kg}{ }^{-1}\right)$ measured after exposure of pre-corroded aluminum alloy 1100 coupons to gamma radiation $\left(46 \mathrm{~Gy} \mathrm{~min}^{-1}\right.$ ) at ambient temperature at $50 \%$ relative humidity as a function of absorbed gamma dose: argon (O); nitrogen (\$o); and air (). Data sourced from reference 13...

Figure 2. Concentration of $\left.\mathrm{H}_{2}(\mu \mathrm{mol} \mathrm{kg})^{-1}\right)$ as a function of absorbed gamma dose from the irradiation of pristine ( $(\infty)$ ) and pre-corroded ( $(\square)$ aluminum alloy 1100 coupons in helium environments at $0 \%(\mathrm{~A})$ and $50 \%$ (B) relative humidity at ambient irradiator temperature. Solid lines are linear fits to data for $G$-value calculation......

Figure 3. Complete data set for the concentration of $\mathrm{H}_{2}\left(\mu \mathrm{mol} \mathrm{kg} \mathrm{kg}^{-1}\right)$ as a function of absorbed gamma dose from the irradiation of pristine (\&) and pre-corroded ( $\square$ ) aluminum alloy 1100 coupons in helium environments at $0 \%$ (A) and 50\% (B) relative humidity at ambient irradiator temperature. Solid lines are linear fits to data for $G$-value calculation.

\section{TABLES}

Table 1. Comparison of $\mathrm{H}_{2} G$-values for gamma irradiated pristine and pre-corroded aluminum alloy 1100 coupons in argon and helium environments at $0 \%$ and $50 \%$ relative humidity. Argon $G$-values were sourced from reference 13 . Helium $G$-values were calculated from linear fits using $\mathrm{H}_{2}$ data points $\leq 20 \mu \mathrm{L}$.

Table 2. Complete preliminary helium environment $\mathrm{H}_{2}$ data set from the irradiation of pristine and pre-corroded aluminum alloy 1100 coupons. $* 20 \mu \mathrm{L}$ is the detection limit for the employed analytical method, as detector saturation occurs above this value. 
Page intentionally left blank 


\section{ACRONYMS}

$\begin{array}{ll}\text { ATR } & \text { Advanced Test Reactor } \\ \text { Al-1100 } & \text { aluminum alloy } 1100 \\ \text { ASNF } & \text { aluminum-clad spent nuclear fuel } \\ \text { DOE } & \text { Department of Energy } \\ \mathrm{E}_{\gamma} & \text { gamma radiation energy } \\ \text { eV } & \text { electron volts } \\ \mathrm{GC} & \text { gas chromatography } \\ \mathrm{Gy} \text { min }^{-1} & \text { Grays per minute } \\ \mathrm{H}_{2} & \text { molecular hydrogen } \\ \mathrm{He} & \text { helium excited state } \\ \mathrm{He}{ }^{\bullet+} & \text { ionized helium } \\ \mathrm{HFIR} & \text { High Flux Isotope Reactor } \\ \mathrm{INL} & \text { Idaho National Laboratory } \\ \mathrm{kGy} & \text { kilo Gray } \\ \mathrm{MeV} & \text { mega electron volts } \\ \tau_{1 / 2} & \text { half-life } \\ { }^{\circ} \mathrm{C} & \text { degrees Celsius } \\ \mu \mathrm{L} & \text { microliter } \\ \mu \mathrm{mol} \mathrm{J}-1 & \text { micromoles per Joule } \\ & \end{array}$


Page intentionally left blank 


\section{INTRODUCTION}

Aluminum-based alloys have been used as fuel cladding for a variety of nuclear reactors in the United States (U.S.) because of their low thermal neutron capture cross-sections, high thermal conductivity, and corrosion-resistant properties [1]. For example, the Idaho National Laboratory (INL) Advanced Test Reactor (ATR) and the Oak Ridge National Laboratory High Flux Isotope Reactor (HFIR) both employ aluminum-clad fuel elements. Consequently, the U.S. Department of Energy (DOE) is currently managing the storage of $\sim 13$ metric tons of aluminum-clad spent nuclear fuel (ASNF), and some of this ASNF will be placed in helium-backfilled canisters for extended ( $>50$ years) dry storage [2-4]. Assessment of this strategy is currently underway, and the amount of generation of radiolytic molecular hydrogen $\left(\mathrm{H}_{2}\right)$ is a key criterion of this evaluation.

The inherent ASNF radiation field promotes radiolysis of the surrounding environment, which, alongside the presence of hydrated aluminum oxyhydroxide corrosion layers (e.g., boehmite, gibbsite, and bayerite) on the cladding surface results in the formation of $\mathrm{H}_{2}$ [5-13]. The generation of $\mathrm{H}_{2}$ in the envisioned storage canister environment, though expected, is not ideal, as it may lead to pressurization and the formation of explosive and flammable gas mixtures. Consequently, an experimental research effort was initiated, as part of the "Technical Considerations and Challenges for Extended ( $>50$ years) Dry Storage of ASNF" program, to investigate the influence of several parameters (absorbed dose, extent of corrosion, gaseous environment, humidity, and temperature) on the radiolytic formation of $\mathrm{H}_{2}$ from the gamma irradiation of aluminum coupons. This initiative ("Task 2 - Oxyhydroxide Layer Radiolytic Gas Generation Resolution") demonstrated that the yield of $\mathrm{H}_{2}$ increased with absorbed dose, pre-corrosion (versus pristine), humidity (up to $\sim 50 \%$ relative humidity), and temperature [13]. Interestingly, $\mathrm{H}_{2}$ formation was found to be sensitive to the gaseous environment (air, nitrogen, or argon) present during irradiation, as shown by Figure 1.

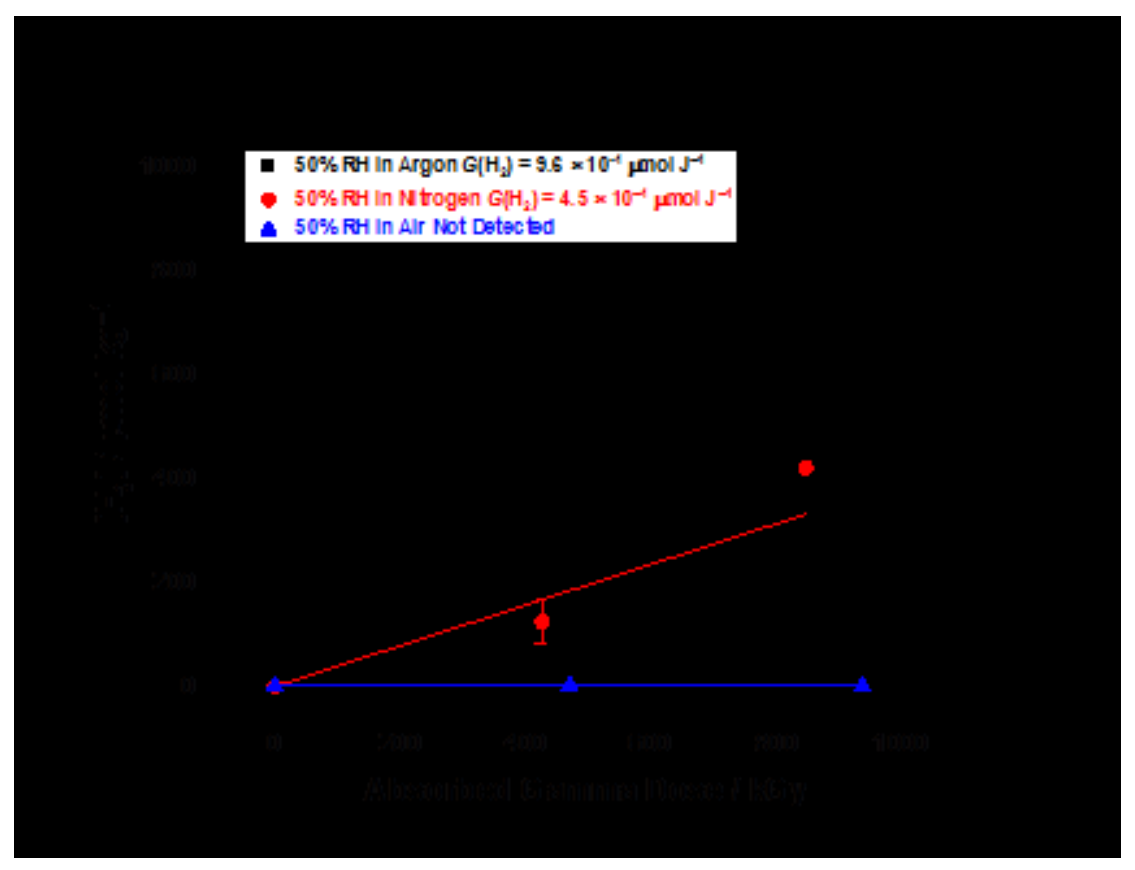

Figure 1. Concentration of $\mathrm{H}_{2}\left(\mu \mathrm{mol} \mathrm{kg} \mathrm{kg}^{-1)}\right.$ measured after exposure of pre-corroded aluminum alloy 1100 coupons to gamma radiation $\left(46 \mathrm{~Gy} \mathrm{~min}^{-1}\right)$ at ambient temperature at $50 \%$ relative humidity as a function of absorbed gamma dose: argon (O); nitrogen (s); and air (ㅁ) [13]. 
This study demonstrated that the highest radiolytic of $\mathrm{H}_{2}$ yield was measured for the most chemically inert gaseous environment, argon. This observation was concerning as the current intention is for helium to be used as the back-fill gas for the standard DOE canister for the extended dry storage of ASNF. Helium is also a chemically inert gas but has a far greater first ionization energy than argon $(24.59 \mathrm{eV}$ versus $15.76 \mathrm{eV}$, respectively). The implication is that helium may promote the formation of a larger yield of $\mathrm{H}_{2}$ than is currently accounted for by the program's complementary modeling component ("Task 3 Sealed and Vented System Episodic Breathing and Gas Generation Prediction"), which may ultimately lead to the higher canister pressures than originally predicted [2-4].

To this end, we report preliminary $\mathrm{H}_{2}$ data from the gamma irradiation of pristine and pre-corroded aluminum alloy 1100 (Al-1100) coupons in helium environments at ambient temperature at $0 \%$ and 50\% relative humidity, to evaluate the impact of helium on radiolytic $\mathrm{H}_{2}$ production.

\section{EXPERIMENTAL METHODS}

\subsection{Materials}

Aluminum alloy 1100 coupons (Al-1100, $2.5 \mathrm{~cm} 0.65 \mathrm{~cm} 0.15 \mathrm{~cm}$ ) were purchased from Metals Samples Company - Alabama Specialty Products, Inc. Acetone (HPLC Plus, $\geq 99.9 \%$ ) and ethanol (absolute, $\geq 99.8 \%$ ) were supplied by MilliporeSigma. Helium was purchased in its highest available purity from Norco. Ultra-pure water $(18.2 \mathrm{M} \Omega \mathrm{cm})$ was used for all water applications. All Al-1100 coupons were cleaned, weighed, pre-corroded, and weighed again as previously described [13].

\subsection{Gamma Irradiations}

Gamma irradiations were performed using the INL Center for Radiation Chemistry Research Foss Therapy Services Cobalt-60 Irradiator unit. Samples comprised individually flame-sealed glass ampules containing a single pristine or pre-corroded Al-1100 coupon in a helium gaseous environment at either $0 \%$ or $50 \%$ relative humidity. Samples were loaded in a bespoke multiposition sample holder and irradiated at ambient irradiator temperature $\left(\sim 45^{\circ} \mathrm{C}\right.$, as determined using a calibrated NI USB-TC01 Single Channel Temperature Input Device with K-type thermocouples) over several days to achieve the desired absorbed gamma doses. Dosimetry was determined for each sample position by Fricke solution $[14,15]$ and corrected for the radioactive decay of cobalt $-60\left(\tau_{1 / 2}=5.27\right.$ years; $\mathrm{E}_{\gamma 1}=1.17 \mathrm{MeV}$ and $\mathrm{E}_{\gamma 1}=$ $1.33 \mathrm{MeV})$ and aluminum electron density $(0.8673)[13,16]$.

\subsection{Gas Chromatography}

An SRI 8610 model GC instrument equipped with a reduction gas detector (RGD) [17] was employed for all reported $\mathrm{H}_{2}$ measurements and used in a "crush tube" configuration as previously described [18]. This method has an estimated error of $\leq 10 \%$ and a $\mathrm{H}_{2}$ sensitivity limit of $1 \mu \mathrm{L}$ [18] and an upper

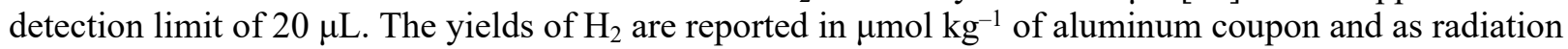
chemical yields $-G$-values - in SI units of $\mu \mathrm{mol} \mathrm{J} \mathrm{J}^{-1}\left(1 \mu \mathrm{mol} \mathrm{J}^{-1}=9.62(\text { molecule } 100 \mathrm{eV})^{-1}\right)$ as calculated from linear fits to data.

\section{RESULTS AND DISCUSSION}

The radiolytic formation of $\mathrm{H}_{2}$ from the gamma irradiation of pristine and pre-corroded Al-1100 coupons in He environments is shown in Figure 2. The complete data set is given in Table 2 in Appendix A. 


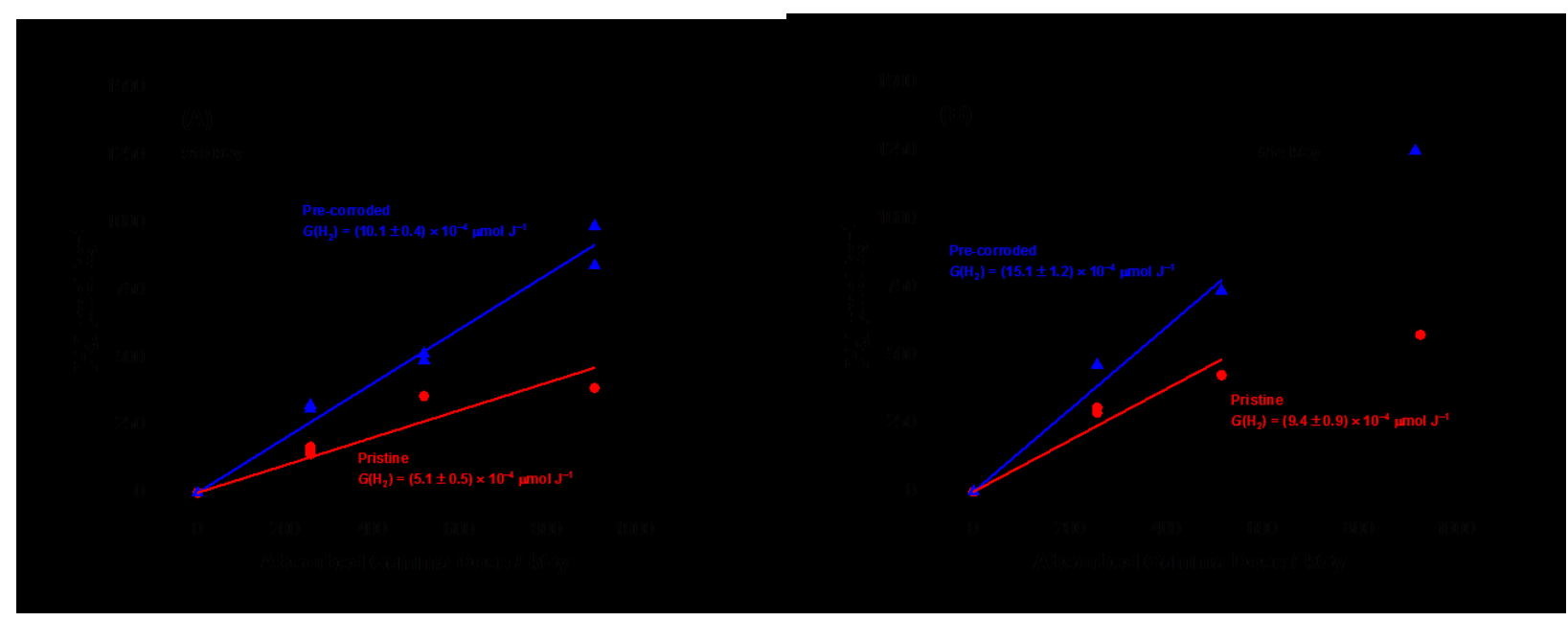

Figure 2. Concentration of $\mathrm{H}_{2}\left(\mu \mathrm{mol} \mathrm{kg}{ }^{-1}\right)$ as a function of absorbed gamma dose from the irradiation of pristine (s) and pre-corroded ( $(\square)$ aluminum alloy 1100 coupons in helium environments at $0 \%$ (A) and $50 \%$ (B) relative humidity at ambient irradiator temperature. Solid lines are linear fits to data for $G$-value calculation.

These trends are predominantly a consequence of radiolytic processes that occur at the Al-1100 coupon surface (M) following radiolytic production, diffusion, and reaction of excitons $\left(\mathrm{h}^{+}\right.$and $\left.\mathrm{e}^{-}\right)$. These reactions include the generation of $\mathrm{H}_{2}$ via the oxidation of adsorbed water by hole transfer $\left(\mathrm{h}^{+}\right)$and abstraction reactions, generalized by equations 1-7 [19-22]:

$$
\begin{gathered}
\mathrm{M} m \mathrm{~h}^{+}+\mathrm{e}^{-} \\
\mathrm{h}^{+}+\mathrm{H}_{2} \mathrm{O} \rightarrow \mathrm{OH}^{-}+2 \mathrm{H}^{+} \\
\mathrm{h}^{+}+\mathrm{M}-\mathrm{OH} \rightarrow \mathrm{M}-\mathrm{O}^{\bullet}+\mathrm{H}^{+} \\
\mathrm{H}^{+}+\mathrm{e}^{-} \rightarrow \mathrm{H}^{\cdot} \\
\mathrm{H}^{\bullet}+\mathrm{M}-\mathrm{OH} \rightarrow \mathrm{M}-\mathrm{OH} \cdot \mathrm{H}^{-} \\
\mathrm{H}^{\cdot}+\mathrm{M}-\mathrm{OH} \cdots \mathrm{H} \rightarrow \mathrm{M}-\mathrm{OH}+\mathrm{H}_{2} \\
\mathrm{H}^{\bullet}+\mathrm{H}^{\cdot} \rightarrow \mathrm{H}_{2} .
\end{gathered}
$$

The concentration of $\mathrm{H}_{2}$ increases linearly with absorbed gamma dose until a steady-state concentration is reached, at which point the precursors to $\mathrm{H}_{2}$ are depleted and $\mathrm{H}_{2}$ becomes progressively more involved in radiolytic processes (e.g., equations 8-10) and dissociation at the materials surface (equations 11-12 [23,24]):

$$
\begin{gathered}
\mathrm{H}_{2} \text { m } \mathrm{H}^{\bullet}, \mathrm{H}_{2}^{+}, \mathrm{e}^{-} \\
\mathrm{H}_{2}+\mathrm{M}-\mathrm{O} \bullet \rightarrow \mathrm{M}-\mathrm{OH}+\mathrm{H}^{\bullet} \\
\mathrm{H}^{\bullet}+\mathrm{M}-\mathrm{OH} \rightarrow \mathrm{M}+\mathrm{H}_{2} \mathrm{O} \\
\mathrm{H}_{2}+\mathrm{M} \rightarrow \mathrm{M}+\mathrm{H}^{\bullet}+\mathrm{H}^{\bullet}(\text { homolytic }) \\
\mathrm{H}_{2}+\mathrm{M} \rightarrow \mathrm{M}+\mathrm{H}^{-}+\mathrm{H}^{+} \text {(heterolytic) } .
\end{gathered}
$$

Our previous nitrogen and argon environment studies were irradiated to doses up to 1.0 MGy, within which $\mathrm{H}_{2}$ production exhibited a linear response to absorbed dose for all system permutations [13]. Here we were able to attain sufficiently high gamma doses ( $>1.0 \mathrm{MGy})$ for $\mathrm{H}_{2}$ production to deviate from linearity, as demonstrated by the pristine coupon data shown in Figure 2 (B) and Figure 3 in Appendix B, which is indicative of the amount of $\mathrm{H}_{2}$ approaching a steady-state concentration. Although our pre- 
corroded coupons also exhibited deviation from linearity, these values were above our upper limit of detection $(20 \mu \mathrm{L})$ and, as such, are not reported here. However, follow-up experiments, using an alternative $\mathrm{GC}$ method with a higher upper limit, are underway to further evaluate this deviation in $\mathrm{H}_{2}$ yield for pre-corroded coupons. These steady-state observations are critical for the modeling component of the "Technical Considerations and Challenges for Extended ( $>50$ years) Dry Storage of ASNF" program, as $G$-values only provide an initial rate of species production, while steady-state data provide a means to evaluate the chemical reaction set employed by the model for the prediction of $\mathrm{H}_{2}$ production over decades of accumulated dose.

Concerning the radiolytic yield of $\mathrm{H}_{2}$, irradiation of Al-1100 coupons in helium environments afforded higher yields of $\mathrm{H}_{2}$ compared to the relatively high yields reported for complementary argon environments [13], as shown in Table 1.

Table 1. Comparison of $\mathrm{H}_{2} G$-values for gamma irradiated pristine and pre-corroded aluminum alloy 1100 coupons in argon and helium environments at $0 \%$ and $50 \%$ relative humidity. Argon $G$-values were sourced from [13]. Helium $G$-values were calculated from linear fits using $\mathrm{H}_{2}$ data points $\leq 20 \mu \mathrm{L}$.

\begin{tabular}{l|l|l|l}
\hline \multirow{2}{*}{ Coupon state } & \multirow{2}{*}{ Gaseous environment } & $\begin{array}{l}\text { Relative humidity } \\
(\%)\end{array}$ & $\begin{array}{l}\boldsymbol{G}\left(\mathbf{H}_{\mathbf{2}}\right) \\
\left(10^{-4} \mu \mathrm{mol} \mathrm{J}^{-1}\right)\end{array}$ \\
\hline \multirow{3}{*}{ Pristine } & \multirow{2}{*}{ Ar } & 0 & $3.6 \pm 0.3$ \\
\cline { 2 - 4 } & \multirow{2}{*}{$\mathrm{He}$} & 50 & $7.3 \pm 0.3$ \\
\hline \multirow{3}{*}{ Pre-corroded } & \multirow{2}{*}{$\mathrm{Ar}$} & 0 & $5.1 \pm 0.5$ \\
\cline { 2 - 4 } & \multirow{2}{*}{$\mathrm{He}$} & 0 & $9.4 \pm 0.9$ \\
\cline { 3 - 4 } & & 50 & $7.3 \pm 0.8$ \\
\hline
\end{tabular}

Argon was shown to yield higher $\mathrm{H}_{2}$ yields than both complementary air and nitrogen systems [13], which was attributed to the inability of argon to chemically interfere with radiolytic processes occurring at the material's surface (e.g., equations 1-8) and directly decompose $\mathrm{H}_{2}$ by charge transfer (equation 14):

$$
\begin{gathered}
\mathrm{Ar} m \mathrm{Ar}^{\bullet+}+\mathrm{e}^{-} \\
\mathrm{Ar}^{\bullet+}+\mathrm{H}_{2} \rightarrow \mathrm{Ar}+\mathrm{H}_{2}{ }^{\bullet+},
\end{gathered}
$$

owing to their similarity in first ionization energy: $\operatorname{argon}=15.76 \mathrm{eV}$ and $\mathrm{H}_{2}=15.4 \mathrm{eV}$ [25]. The increase in $G\left(\mathrm{H}_{2}\right)$ for helium environments ranged between $28 \%$ and $58 \%$, relative to values for argon environments, Table 1 . This enhancement is attributed to helium possessing a significantly higher first ionization energy (24.59 eV [25]) relative to argon. Consequently, less energy is expected to be transferred from the Al-1100 surface to a helium medium and is thus more available for promoting surface-mediated radiolytic processes. Further, any energy absorbed to a helium medium can be expected to be transferred to the Al-1100 surface, radiolytically generated species, and other molecules in the gas phase, by processes such as Penning ionization (Equations 15-16):

$$
\begin{gathered}
\mathrm{He} m \mathrm{He}^{*} \\
\mathrm{He}^{*}+\mathrm{M} \rightarrow \mathrm{He}+\mathrm{h}^{+}+\mathrm{e}^{-},
\end{gathered}
$$

whereby the radiolytically generated excited states of helium $\left(\mathrm{He}^{*}\right)$ possess energies in excess of the ionization potential of chemical species they collide with, thereby inducing ionization via de-excitation of the He*. This effect has been well characterized for ionization of several noble gases ( $\mathrm{Ar}, \mathrm{Kr}$, and $\mathrm{Xe}$ ), other small molecules (e.g., $\mathrm{H}_{2}$ and $\mathrm{CH}_{4}$ ), and some metals (e.g., $\mathrm{Li}$ and $\mathrm{Na}$ ) by He* [26-33]. This 
particular process may also be the reason for the onset of a steady-state $\mathrm{H}_{2}$ concentration at higher doses for pristine coupons in Figure 2 (B) and Figure 3 in Appendix B. Both ionized helium $\left(\mathrm{He}^{\cdot+}\right)$ and $\mathrm{He}^{*}$ have energies in sufficient excess of the ionization potential of $\mathrm{H}_{2}$ to promote its decomposition via the proposed reactions below:

$$
\begin{gathered}
\mathrm{He}^{\bullet+}+\mathrm{H}_{2} \rightarrow \mathrm{He}+\mathrm{H}_{2}{ }^{\bullet+} \\
\mathrm{He}^{*}+\mathrm{H}_{2} \rightarrow \mathrm{He}+\mathrm{H}_{2}{ }^{\cdot+}+\mathrm{e}^{-} .
\end{gathered}
$$

\section{CONCLUSIONS}

The purpose of this investigation was to evaluate the effect of helium gas on the radiolytic yield of $\mathrm{H}_{2}$ from irradiated pristine and pre-corroded Al-1100 coupons, as helium has been proposed as the back-fill medium for the standard DOE canister for extended dry storage of ASNF. Here, we have demonstrated that helium gas promotes the radiolytic formation of greater yields of $\mathrm{H}_{2}$, up to $58 \%$, relative to previously investigated argon systems. Further, the presented data exhibit deviation from linearity with increasing dose, indicating the approach to a steady-state $\mathrm{H}_{2}$ concentration, which is a critical value for evaluating complementary modeling efforts. Overall, the presented helium $G$-value data and dose dependence trends are useful as preliminary seeds for computer calculations, while follow-on helium studies are necessary and underway to evaluate this effect to higher doses.

\section{ACKNOWLEDGMENTS}

This work was supported by the U.S. Department of Environmental Management, Office of Technology Development, under contract DE-AC07-05ID14517.

\section{REFERENCES}

\section{7.}

(1) Corrosion of Research Reactor Aluminium Clad Spent Nuclear Fuel in Water. IAEATECDOC-1637, 2009.

(2) United States Department of Energy, 1998a. Preliminary Design, Specification for Department of Energy Standardized Spent Nuclear Fuel Canisters. Idaho Falls, Vol I Design Specification.

(3) ECAR 4632, Spencer Snow, Supplemental Evaluation of the DOE Standard SNF Canister for Accidental Drops, 8/2019.

(4) United States Department of Energy, 1998b. Preliminary Design, Specification for Department of Energy Standardized Spent Nuclear Fuel Canisters. Idaho Falls, Vol II Rationale document.

(5) Wittman, R. Radiolysis Model Sensitivity Analysis for a Used Fuel Storage Canister. FCRDUFD-2013-000357, 2013.

(6) Wittman, R.S., Hanson, B.D., Radiolysis Model Analysis for a Used Fuel Storage Canister. IHLRWM, 2015.

(7) Kaddissy, J.A., Esnouf, S., Durand, D., Saffre, D., Foy, E., Renault, J-P., 2017. Radiolytic Events in Nanostructured Aluminum Hydroxides. J. Phys. Chem. C, 121, 6365-6373.

(8) LaVerne J.A., Huestis, P.L., 2019. H Atom Production and Reaction in the Gamma Radiolysis of Thermally Modified Boehmite. J. Phys. Chem. C, 123 (34), 21005-21010.

(9) Reiff, S.C., LaVerne, J.A., 2017. Radiolysis of Water with Aluminum Oxide Surfaces. Rad. Phys. Chem., 131, 46-50.

(10) Fisher, D.L., Westbrook, M.L., Sindelar, R.L., 2012. Test Results from Gamma Irradiation of Aluminum Oxyhydroxides. SRNL-STI-2011-00602.

(11) Westbrook, M.L., Sindelar, R.L., Fisher, D.L., 2015. Radiolytic Hydrogen Generation from Aluminum Oxyhydroxide Solids: Theory and Experiment. J. Radioanal Nucl. Chem. 303, 81-86.

(12) $\mathrm{Hu}, \mathrm{T} . \mathrm{A} ., 2$ 2012. Improved Model for Hydrogen Generation Rate of Radioactive Waste at the Hanford Site. Nucl. Tech., 178, 39-54, DOI: 10.13182/NT12-A13546. 
(13) Parker-Quaife, E.H., Verst, C., Heathman, C.R., Zalupski, P.Z., Horne, G.P., 2020. Radiation-

Induced Molecular Hydrogen Gas Generation in the Presence of Aluminum Alloy 1100. Rad. Phys. Chem., 77, 109117, DOI: 10.1016/j.radphyschem.2020.109117.

(14) Fricke H., Hart, E.J., 1935. The Oxidation of $\mathrm{Fe}^{2+}$ to $\mathrm{Fe}^{3+}$ by the Irradiation with $X$-Rays of Solutions of Ferrous Sulfate in Sulfuric Acid. J. Chem. Phys., 3, 60-61.

(15) Barr, N.F., Schuler, R.H., 1959. The Dependence of Radical and Molecular Yields on Linear Energy Transfer in the Radiation Decomposition of 0.8 N Sulfuric Acid Solutions. J. Phys. Chem., 63, 808-813.

(16) Spinks J.W.T., Woods, R.J., An Introduction to Radiation Chemistry, Third Edition, WileyInterscience, New York, 1990.

(17) https://www.srigc.com/cn/downloads/41/RGD.pdf

(18) Parker-Quaife, E.H., Horne, G.P., 2020. Milestone 2.7: Evaluation of Techniques for the Measurement of Molecular Hydrogen Gas in Helium Matrices, INL/EXT-20-60008.

(19) Buxton, G.V., Greenstock, C.L., Helman, W.P., Ross, A.B., 1988. Critical Review of Rate Constants for Reactions of Hydrated Electrons, Hydrogen Atoms and Hydroxyl Radicals $\left({ }^{\circ} \mathrm{OH} /{ }^{\circ} \mathrm{O}^{-}\right)$ in Aqueous Solution. J. Phys. Chem. Ref. Data, 17, 513-886.

(20) Milosavljevic, B.H., Thomas, J.K., 2003. Reactions of Electrons on the Surface of $\gamma-\mathrm{Al}_{2} \mathrm{O}_{3}$. A Pulse Radiolytic Study with 0.4 MeV Electrons. J. Phys, Chem. B, 107, 11907-11910.

(21) Thomas, J.K., 2005. Physical Aspects of Radiation-Induced Processes on $\mathrm{SiO}_{2}, \gamma-\mathrm{Al}_{2} \mathrm{O}_{3}$, Zeolites, and Clays. Chem. Rev., 105, 1683-1734.

(22) Le Caer, S., 2011. Water Radiolysis: Influence of Oxide Surfaces on $\mathrm{H}_{2}$ Production under Ionizing Radiation. Water, 3, 235-253, DOI: 10.3390/w3010235.

(23) Joubert, J., Salameh, A., Krakoviack, V., Delbecq, F., Sautet, P., Coperet, C., Basset J.M., 2006. Heterolytic Splitting of H2 and CH4 on y-Alumina as a Structural Probe for Defect Sites. J. Phys. Chem. B, 110, 23944-23950.

(24) Garcia-Melchor, M., Lopez, N., 2014. Homolytic Products from Heterolytic Paths in $\mathrm{H}_{2}$ Dissociation on Metal Oxides: The Example of $\mathrm{CeO}_{2}$. J. Phys. Chem. C, 118, 10921-10926.

(25) Clifton G., 1920. Ionization potentials of argon, nitrogen, carbon monoxide, helium, hydrogen and mercury and iodine vapors. Physical Review, 16.1, 41-53.

(26) Jesse, W.P., Sadauskis, 1952. Alpha-Particle Ionization in Mixtures of the Noble Gases. Phys. Rev., $88,417-418$.

(27) Bell, K.L., Dalgarno, A., Kingston, A.E., 1968. Penning ionization by metastable helium atoms. $J$. Phys. B (Proc. Phys. Soc.), 2 (1), 18-22.

(28) Okazaki, K., Oku, E., Sato, S., 1976. Degradation Spectra and the G-values for the Ionization and Excitation of the Mixtures of Noble Gases. Bull. Chem. Soc. Japan, 49 (5), 1230-1235.

(29) Ueno, T., Yokoyama, A., Takao, S., Hatano, Y., 1980. De-excitation Rate Constants of $\operatorname{He}\left(2{ }^{3} \mathrm{~S}\right)$ by Atoms and Molecules as Studied by the Pulse Radiolysis Method. Chem. Phys., 45, 261-271.

(30) Ukai, M., Tanaka, Y., Koizumi, H., Shinsaka, K., Hantano, Y., 1986, Temperature dependence of the rate constants for deexcitation of $\mathrm{He}\left(2{ }^{1} \mathrm{P}\right)$ by $\mathrm{SF}_{6}$ and Ar. J. Chem. Phys., 84, 5575-5579.

(31) Koizumi, H., Ukai, M., Tanaka, Y., Shinsaka, K., Hatano, Y., 1998. Temperature dependence of the deexcitation of $\mathrm{He}\left(2{ }^{3} \mathrm{~S}\right)$ by atoms and molecules as studies by pulse radiolysis method. J. Chem. Phys., 85, 1932-1937.

(32) Ukai, M., Yoshida, H., Morishima, Y., Nakazawa, H., Shinsaka, K., Hatano, Y., 1989. Deexcitation of $\mathrm{He}\left(2^{1} \mathrm{P}\right)$ in collisions with rare gas atoms. J. Chem. Phys., 90 (9), 4865-4874.

(33) Cooper, R., Zauer, M.C., 1994, Subexcitation electron interactions in rare gases: Production of electronic excited states in helium or neon mixtures with argon, krypton, or xenon. Physical Review A, 50 (6), 4812-4818.

\section{Appendix A}


Table 2. Complete preliminary helium environment $\mathrm{H}_{2}$ data set from the irradiation of pristine and precorroded aluminum alloy 1100 coupons. $* 20 \mu \mathrm{L}$ is the detection limit for the employed analytical method, as detector saturation occurs above this value.

\begin{tabular}{|c|c|c|c|c|}
\hline Coupon state & $\begin{array}{l}\text { Relative } \\
\text { humidity } \\
(\%)\end{array}$ & $\begin{array}{l}\text { Absorbed } \\
\text { gamma dose } \\
(\mathrm{kGy})\end{array}$ & $\begin{array}{l}\mathbf{H}_{2} \text { volume } \\
(\mu \mathrm{L})\end{array}$ & $\begin{array}{l}\boldsymbol{G}\left(\mathbf{H}_{2}\right) \\
\left(\mu \mathrm{mol} \mathrm{J}{ }^{-1}\right)\end{array}$ \\
\hline \multirow{11}{*}{ Pristine } & 1 & 258.36 & 2.22 & 0.00066 \\
\hline & 1 & 258.36 & 2.00 & 0.00055 \\
\hline & 1 & 258.36 & 2.07 & 0.00061 \\
\hline & 1 & 518.86 & 4.74 & 0.00069 \\
\hline & 1 & 909.83 & 5.49 & 0.00043 \\
\hline & 2 & 1864.70 & 9.38 & 0.00033 \\
\hline & 4 & 4977.29 & 16.62 & 0.00023 \\
\hline & 47 & 256.33 & 4.36 & 0.00120 \\
\hline & 47 & 256.33 & 4.37 & 0.000113 \\
\hline & 46 & 514.53 & 6.08 & 0.00083 \\
\hline & 47 & 927.89 & 8.64 & 0.00062 \\
\hline \multirow{11}{*}{ Corroded } & 2 & 258.36 & 5.31 & 0.00126 \\
\hline & 2 & 258.36 & 5.10 & 0.00120 \\
\hline & 2 & 518.86 & 8.67 & 0.00099 \\
\hline & 2 & 518.86 & 8.14 & 0.00095 \\
\hline & 2 & 909.83 & 14.21 & 0.00093 \\
\hline & 2 & 909.83 & 16.41 & 0.00109 \\
\hline & 2 & 1864.70 & $<20^{*}$ & $-*$ \\
\hline & 2 & 4641.10 & $<20^{*}$ & $-*$ \\
\hline & 51 & 256.33 & 7.88 & 0.00182 \\
\hline & 53 & 514.53 & 12.53 & 0.00143 \\
\hline & 52 & 917.20 & 20.66 & 0.00136 \\
\hline
\end{tabular}




\section{APPENDIX B}

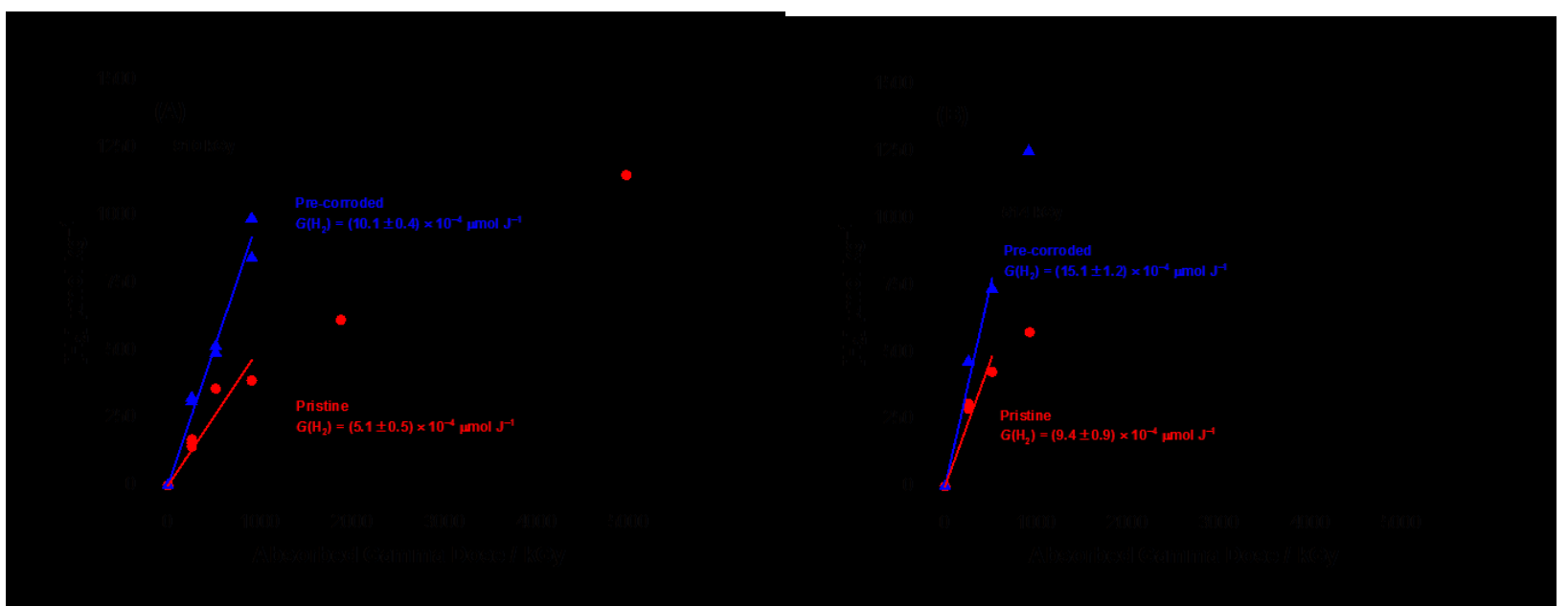

Figure 3. Complete data set for the concentration of $\mathrm{H}_{2}\left(\mu \mathrm{mol} \mathrm{kg}{ }^{-1}\right)$ as a function of absorbed gamma dose from the irradiation of pristine $(\infty)$ ) and pre-corroded ( $(\square)$ aluminum alloy 1100 coupons in helium environments at $0 \%(\mathrm{~A})$ and $50 \%$ (B) relative humidity at ambient irradiator temperature. Solid lines are linear fits to data for $G$-value calculation. 